\title{
Reporting sex as a biologic variable in research published in the Journal of Vascular Surgery Publications
}

Recent studies have shown that most basic science and translational research is conducted on male animals and male cells, even when studying diseases more prevalent in women. ' Clinical research studies also frequently lack sex-based reporting and sex-based analysis of outcomes. $^{2,3}$ The National Institutes of Health $(\mathrm{NIH})$ now requires that sex be considered as a variable in all $\mathrm{NIH}$-funded research. ${ }^{4}$ Given these developments, the Surgery Journals Editors Group published a statement that addresses the importance of conducting sexinclusive biomedical and clinical research to improve health outcomes of men and women. ${ }^{5}$

We, the Editors of the Journal of Vascular Surgery Publications that include the Journal of Vascular Surgery, Journal of Vascular Surgery: Venous and Lymphatic Disorders, and the Journal of Vascular Surgery Cases and Innovative Techniques, support the statement of the surgical journal editors that requires uniform, defined sex-based reporting and sex-based analysis of data of human, animal, tissue, and cell research in all manuscripts published in our journals. If only one sex is reported, the authors must justify the reason why only a single-sex study was conducted. We believe this new Journal of Vascular Surgery Publications policy is consistent with the standards of other high-quality peer-reviewed medical and surgical journals and it will address an important issue that has only recently been recognized.

\author{
Peter Gloviczki, MD \\ Editor-in-Chief \\ Peter F. Lawrence, MD \\ Senior Editor
}

\section{REFERENCES}

1. Yoon DY, Mansukhani NA, Stubbs VC, Helenowski IB Woodruff TK, Kibbe MR. Sex bias exists in basic science and translational surgical research. Surgery 2014;156:508-16.

2. U.S. Government Accountability Office. National Institutes of Health: better oversight needed to help ensure continued progress including women in health research; October 22 , 2015. Available at: https://www.gao.gov/products/GAO-16-13. Accessed October 29, 2018.

3. Mansukhani NA, Yoon DY, Teter KA, Stubbs VC, Helenowski IB Woodruff TK, et al. Determining If Sex Bias Exists in Human Surgical Clinical Research. JAMA Surg 2016;151:1022-30.

4. National Institutes of Health Office of Extramural Research Consideration of sex as a biological variable in $\mathrm{NIH}$-funded research; June 9, 2015. Available at: https://grants.nih.gov/ grants/guide/notice-files/not-od-15-102.html. Accessed October 29, 2018

5. Lillemoe KD. Joint statement by the Surgery Journal Editors Group 2018. Ann Surg 2018;267:991.

\footnotetext{
J Vasc Surg Cases and Innovative Techniques 2018;4:341

2468-4287

(C) 2018 Society for Vascular Surgery. Published by Elsevier Inc. This is an open access article under the CC BY-NC-ND license (http://creativecommons.org/ licenses/by-nc-nd/4.0/).

https://doi.org/10.1016/j.jvscit.2018.11.001
} 